\title{
The effect of anaemia and malnutrition on the healing of diabetic foot wound
}

\author{
Ahmed Osmane, MD; Naguib El Askari, MD \\ Department of Vascular Surgery, Alexandria University, Alexandria, Egypt.
}

Background: Anaemia is a common problem in surgical patient, and it is an independent risk factor for blood transfusion, peri-operative infection, mortality and a longer in-patient stay. Diabetic foot wound results from the interaction of several contributory factors, the most important of which is neuropathy. With respect to the management of acute Charcot neuroarthropathy in diabetics, patients with diabetic foot wounds suffer from chronic inflammation, repeated infection, often undergo several invasive or operative treatments, and can have a protracted hospital stay. We hypothesised that, for these reasons, many patients with diabetic foot wound may suffer anaemia, require blood transfusion and suffer from poor nutrition.

Aim of the work: Anaemia and nutritional status assessment as they affect the healing in patients presenting with diabetic foot wounds.

Patients and methods: Two observational studies were undertaken. Initially a retrospective series of 20 patients with diabetic foot wounds. Patient demographics, clinical details, transfusion status and in-patient laboratory haemoglobin values $(\mathrm{Hb})$ were recorded. In a prospective series of 33 patients, laboratory markers and nutritional status were assessed. Infection was excluded and managed appropriately by antibiotics and surgically by wound debridement or amputation. Other factors affecting wound healing were excluded as peripheral arterial diseases or debilitating diseases as renal failure.

Results: In the retrospective series, 17 patients (85\%) were anaemic (100\% females) with average haemoglobin of $5 \mathrm{~g}$ (SD 2.4) below the lower limit of normal for the sex of the patients. Ten patients (50\%) were transfused. The average trigger haemoglobin index was $8.5 \mathrm{~g} / \mathrm{dl}$ (SD 0.8). Patients who were transfused had lower haemoglobin on admission $(p=0.0016)$. Overall, at discharge, most of the patients were anaemic (92\%). In the prospective series on admission, 27 patients (82\%) were anaemic, also anaemic patients had a higher CRP and lower albumin level. 17 patients (52\%) had been scored to be undernourished. Clinical follow up with appropriate dressing of the wounds and calculating the healing rate was observed.

Conclusion: Usually anaemia as well as poor nutrition is the normal event and affecting the healing of diabetic wounds. Multidisciplinary review should be undertaken in all patients.

\section{Introduction:}

Approximately 170 million individuals are affected by diabetes worldwide including 23.6 million in the United States (7-8\% of the population). ${ }^{1}$ In Egypt, the percentage of affected population is reported as high as $20 \%$. Of these individuals, $28.5 \%$ have diabetic peripheral neuropathy. Poor glycaemic control is associated with the presence of neuropathy and increased risk for wounds and amputations. ${ }^{2}$ Wounds of the foot are common in individuals with diabetes, with an annual incidence of $1-2 \%{ }^{3}$

Diabetic foot wound represents a major medical, social and economic problem all over the world. While more than $5 \%$ of diabetic patients have a history of foot ulceration, the cumulative lifetime incidence may be as high as $15 \%$. Ethnic differences exist in both wound and amputation incidences, 
with both being less common in patients of Indian subcontinent origin living in the UK. ${ }^{4,5}$ Diabetic foot wound results from the interaction of several contributory factors, the most important of which is neuropathy. With respect to the management of acute Charcot neuroarthropathy in diabetics, patients with diabetic foot wounds suffer from chronic inflammation, repeated infection, often undergo several invasive or operative treatments, and can have a protracted hospital stay. For these reasons, many patients with diabetic foot wound may suffer anaemia, require blood transfusion and suffer from poor nutrition. ${ }^{6-10}$

Anaemia is a common problem in surgical patient. Prevalence is reported from 5-78\%. Anaemia is an independent risk factor for blood transfusion, peri-operative infection, mortality and a longer in-patient stay. ${ }^{11-13}$ Two main types of anaemia affect surgical patients, iron-deficiency anaemia (IDA) and anaemia of chronic disease (ACD); the latter is more common in chronically ill and hospitalised patients. ACD can be difficult to diagnose, often being regarded as a diagnosis of exclusion. A key feature of ACD is a disruption of normal iron homeostasis initiated by a cytokine-mediated immune response such as in chronic inflammatory disease, during infection or following surgery. ${ }^{14-17}$

Malnutrition is one of the factors affecting wound healing, namely low caloric and protein intake. The relationship between nutritional status and the development of diabetic foot ulcer has been investigated. The wound occurs when injury destroys tissue integrity. In this wound, thousands of cells will die of physical disruption, desiccation on exposure to air, and exposure to non-physiological fluids. Macrophages play an important role in the recognition of injury. In addition, local ischaemia and hypoxia are always present in the centre of the wound and induce the production of lactate, which stimulates cell growth in wounds. Structural elements like collagen and proteoglycans are synthesized in the wound. Wound nutrition, like any massive reconstruction, uses a combination of in-situ and remote synthesis. ${ }^{18-21}$

\section{Aim of the work}

Was to assess anaemia and nutritional status and their effects on healing in patients presenting with diabetic foot wounds.

\section{Patients and methods:}

This study was done at Alexandria University Hospital. Initially, an observational retrospective study of 20 patients presented with diabetic foot wounds was performed over 4 months. Demographic study as regards age and sex was recorded. Also haemoglobin levels and transfusion status were recorded.

The other study was the prospective one, in which data were collected over the subsequent 6 months on 33 patients. In addition, the aim was to assess anaemia and to determine, if possible, the cause of anaemia using certain laboratory tests as the haemoglobin level, mean cell volume (MCV), C reactive protein (CRP), serum urea and creatinine, and serum albumin. Anaemia was defined as a laboratory haemoglobin concentration of less than $11.5 \mathrm{~g} / \mathrm{dl}$ for females and $13 \mathrm{~g} / \mathrm{dl}$ for males. Trigger index was defined as the haemoglobin at which patients were transfused. All patients had their nutritional status assessed by recording the height, weight, body mass index (BMI) using a validated scoring system Table(1). Clinical wound assessment as regards the size and healing rate was performed weekly. Patients on dialysis with known renal failure were excluded.

\section{Results:}

Of the 20 patients in the retrospective series, there were 12 females (60\%) and 18 males (40\%). Average age was 57 years (SD 12.6). All patients underwent surgery in the form of debridement. On admission, 17 patients (85\%) were anaemic (100\% females) with an average haemoglobin of $5 g$ (SD 2.4) below the lower limit of normal for the sex of the patients. Only 3 patients (15\%) were not anaemic (100\% males) on admission with an average haemoglobin of $0.8 \mathrm{~g}$ (SD 0.5) above the lower limit of normal for the sex of the 


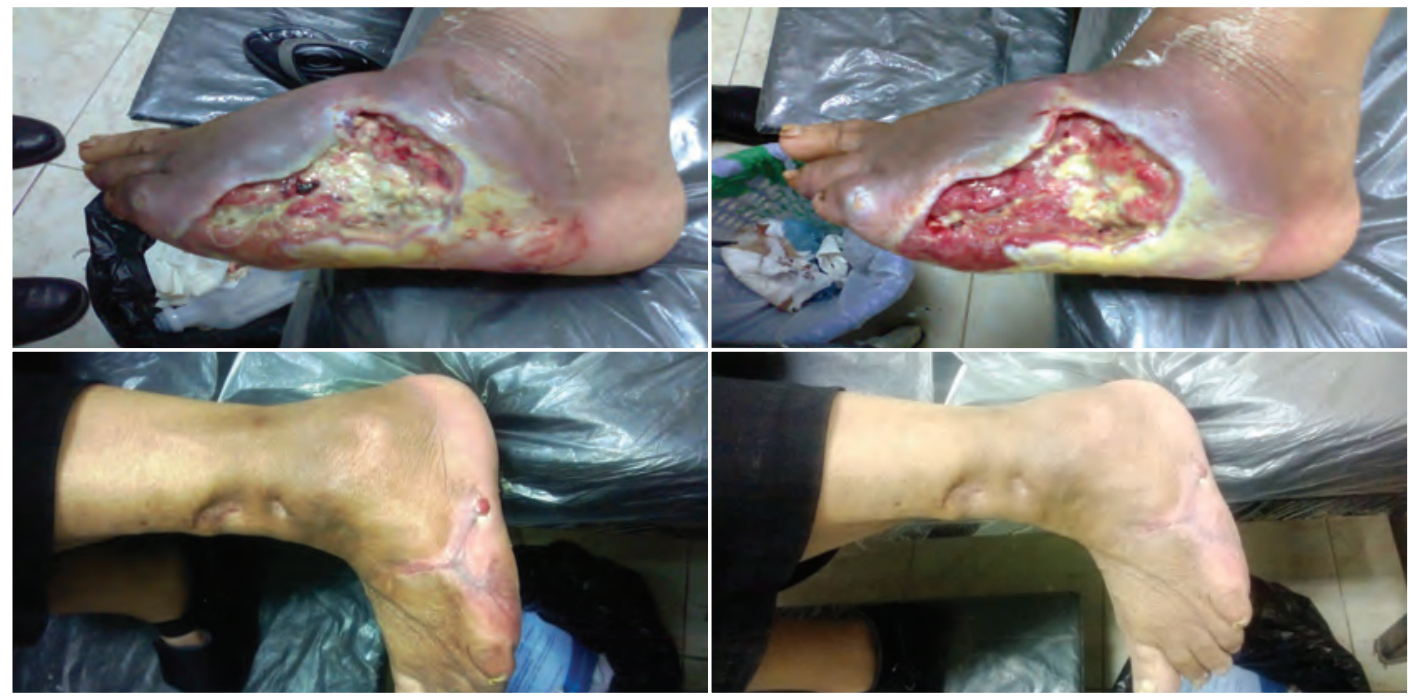

Figure (1): Photos of diabetic foot wound; first (0 week), second (3 weeks), third (20 weeks), and fourth (22 weeks).

Table(1); The scoring system.

\begin{tabular}{|cc|}
\hline Body mass index $(\mathrm{kg} / \mathrm{m} 2)$ & 0 \\
$>20$ & 2 \\
$18-20$ & 3 \\
$<18$ & \\
Food intake & 0 \\
No & 2 \\
Yes & 1 \\
Not known & \\
Unintentional weight loss & 0 \\
No & 1 \\
Up to 3 kg & 2 \\
More than 3 kg & \\
Stress factor/ illness severity & 1 \\
None & 2 \\
Moderate & 3 \\
Severe & \\
\hline
\end{tabular}

Table(2); Risk factors at admission.

\begin{tabular}{|l|l|}
\hline \multicolumn{1}{|c|}{ Risk factor } & \multicolumn{1}{c|}{ N (\%) } \\
\hline Diabetes mellitus & $33(100 \%)$ \\
Hypertension & $14(42 \%)$ \\
Hyperlipidaemia & $19(58 \%)$ \\
Previous MI/CVA & $3(9 \%)$ \\
Smoking & $12(36 \%)$ \\
\hline
\end{tabular}

patients. Ten patients (50\%) were transfused a median of two units (range 1-6 units), a total of 28 units. The average trigger haemoglobin index was $8.5 \mathrm{~g} / \mathrm{dl}$ (SD 0.8). Patients who were transfused had lower haemoglobin on admission $(\mathrm{p}=0.0016)$ and all of them were anaemic on admission (100\%). The average increase in haemoglobin after transfusion 
Table(3); Haematological markers for anaemic and non-anaemic patients at admission.

\begin{tabular}{|l|l|l|l|}
\hline $\begin{array}{l}\text { Haematological } \\
\text { marker }\end{array}$ & $\begin{array}{l}\text { Anaemic } \\
\text { Mean (SD) }\end{array}$ & $\begin{array}{l}\text { Non-anaemic } \\
\text { Mean (SD) }\end{array}$ & $\begin{array}{l}\text { P-value } \\
\text { Significant difference } \\
(\mathrm{P} \leq 0.05)\end{array}$ \\
\hline MCV $(\mathrm{fl})$ & $83(5.6)$ & $93(3.9)$ & 0.0089 \\
\hline CRP $(\mathrm{mg} / \mathrm{l})$ & $62(59.8)$ & $19(16.2)$ & 0.0485 \\
\hline Albumin $(\mathrm{g} / \mathrm{l})$ & $3.3(3)$ & $4.5(41)$ & 0.0119 \\
\hline Creatinine $(\mathrm{mg} / \mathrm{l})$ & $2.1(42)$ & $0.9(22.9)$ & 0.0538 \\
\hline
\end{tabular}

Table (4); Characteristics of wounds.

\begin{tabular}{|l|l|}
\hline Baseline length (cm), mean (SD) & $3.1(2.7)$ \\
\hline Baseline width (cm), mean (SD) & $2.4(1.9)$ \\
\hline Baseline area (cm2), mean (SD) & $7.44(11.5)$ \\
\hline Change in length per week (cm), mean (SD) & $0.3(0.18)$ \\
\hline Change in width per week (cm), mean (SD) & $0.1(0.12)$ \\
\hline Change in area per week (cm2), mean (SD) & $0.03(0.6)$ \\
\hline
\end{tabular}

was $1.1 \mathrm{~g} / \mathrm{dl}$. The non-transfused patients (50\%), their haemoglobin fell on the average of $1.5 \mathrm{~g} / \mathrm{dl}$ (SD 0.5) during their admission. Overall, at discharge, most of the patients were anaemic (92\%).

In the prospective series of 33 patients, there were 19 females (58\%) and 14 males (42\%). Average age was 62 years (SD 12). All patients underwent surgery in the form of debridement of the infected necrotic tissues with or without lay-opened toe amputation (major limb amputation with primary wound closure were excluded). Main complaints on admission were tissue loss (27 patients) and night fever associated with anorexia (13 patients); risk factors are given in Table(2).

On admission, 27 patients (82\%) were anaemic, and those patients had a lower average of MCV than non-anaemic patients. Also anaemic patients had a higher CRP and lower albumin level Table(3).

Nutritional assessment had been performed on all the patients, height and weight were measured and BMI was calculated. 17 patients (52\%) had been scored to be undernourished. Patients who presented anaemic were more likely to be malnourished (nutritional score $>3 ; n=15 ; p=0.049$ ). Length of hospital stay was longer in those patients presented with anaemia and hypoalbuminaemia in order to correct both of them by transfusion and high protein diet (mean 21 days (SD 15) versus non-anaemic 9 days (SD 7) $\mathrm{p}=0.0125$ ). Clinical follow up with appropriate dressing of the wounds with noting the changes towards healthy granulating tissues, and calculating the healing rate was observed as shown in Table(4).

\section{Discussion:}

In this sample of diabetic individuals, anaemia and malnutrition were significantly associated with diabetic foot wounds. Anaemic patients were more likely to be malnourished. Anaemia should be corrected by transfusion and this increases the hospital length of stay. Actually routine haematological markers did not define a cause for the anaemia, although a raised CRP may suggest ACD. Most of the patients were malnourished on admission. Many received blood transfusion during their hospital stay, and most were anaemic on discharge. Haemoglobin usually decreases at discharge in those admitted patients who were not transfused. Although this case series did not assess blood loss at intervention, it did show that most anaemic patients underwent transfusion. Several studies found that ACD is the most common anaemia of chronically ill and hospitalised patients. ${ }^{22-24}$ 
Diabetic patients suffer chronic inflammation from ulceration, and suggesting that they consequently also suffer from anaemia of chronic disease. ${ }^{23,24}$ ACD is better treated by detecting the underlying disease, and its correction may help to reduce the hospital stay. ${ }^{25}$

Data collected for nutritional status is carried on Douglas score which is a tool for risk assessment, however the patients were rarely properly assessed and none had nutritional input. This may indicate that those patients will be better assessed and corrected by dietician. Breslow et $\mathrm{al}^{26}$ compared tubefed patients and noted that the patients with pressure sores were in poorer nutritional condition, as assessed by albumin level, despite of high protein intake. Similar results were found by Green et $\mathrm{al}^{27}$ worked on a community sample of 175 elderly patients, and by Allman et al ${ }^{28}$ evaluated among 286 hospitalised patients above the age of 55 . The 2006 NICE guidance ${ }^{29}$ recommends simple initial assessment and referral to a multidisciplinary nutritional support team.

Our study here high-light the need to look at every aspect of management of wounds in diabetic patients, as they are frequently malnourished and anaemic. Also, a policy should be put that all patients with diabetic foot wound should start on nutritional supplements and be reviewed by the nutritional support team.

\section{Conclusion}

Anaemia as well as poor nutrition is usually the normal event and affecting the healing of diabetic wounds. Multidisciplinary review of the haematological investigations by internist, dietician, and surgeon should be undertaken in all patients.

\section{Reference}

1- Centres for Disease Control and Prevention (2011) National Diabetes Fact Sheet: National Estimates and General Information on Diabetes and Prediabetes in the United States, 2011. US Department of Health and Human Services: Atlanta, GA.

2- Golinko MS, Margolis DJ, Tal A, et al: Preliminary development of a diabetic foot ulcer database from a wound electronic medical record: A tool to decrease limb amputations. Wound Repair Regen 2009; 17: 657-665.

3- Ince P, Kendrick D, Game F, et al: The association between baseline characteristics and the outcome of foot lesions in a UK population with diabetes. Diabet Med 2007; 24: 977-981.

4- Robbins JM, Strauss G, Aron D, Long J, Kuba, J, Kaplan Y: Mortality rates and diabetic foot ulcers: Is it time to communicate mortality risk to patients with diabetic foot ulceration? J Am Podiatr Med Assoc 2008; 98(6): 489-493.

5- Markuson M, Hanson D, Anderson J, et al: The relationship between hemoglobin A (1c) values and healing time for lower extremity ulcers in individuals with diabetes. Adv Skin Wound Care 2009; 22: 365-372.

6- Weiss G, Goodnough LT: Anaemia of chronic disease. $N$ Engl $J$ Med 2005; 352: 1011-1023.

7- Weiss G: Pathogenesis and treatment of anaemia of chronic disease. Blood Rev 2002; 16: 87-96.

8- Wang JJ, Penrod J, Magaziner J, Halm EA, et al: The effect of perioperative anaemia on clinical and functional outcomes in patients with hip fracture. J Orthop Trauma 2004; 18 : 369-374.

9- Roy CN, Andrews NC, Means JR: The anaemia of infection. Baillieres Best Pract Res Clin Haematol 2003; 53: 507-512.

10- Witte MB, Barbul A: General principles of wound healing. Surg Clin North Am 1997; 7: 509-527.

11- Cladellas M, Bruguera J, Comin J, Vila J, et al: Is pre-operative anaemia a risk marker for in-hospital mortality and morbidity after valve replacement? Eur Heart J 2006; 116: 471-479.

12- Napolitano LM: Perioperative anaemia. Surg Clin North Am 2005; 85: 1215-1227.

13- Levin J, Moser R, Tudor IC, et al: Impact of preoperative anaemia on outcome in patients undergoing coronary artery bypass graft surgery. Circulation 2007; 116: 471-479.

14- Malone D, Tracy JK, Dunne JR, Napolitano LM: Perioperative anaemia: An independent risk factor for infection, mortality, and resource utilization in surgery. $J$ Surg Res 2002; 102: 237-244.

15- Myers E, Grady P, Dolan AM: The influence of preclinical anaemia on outcome following total hip replacement. Arch Orthop Trauma 
Surg 2004; 124: 699-701.

16- Duff A, Posses RM, Berlin JA, Spences RK et al: Effect of anaemia and cardiovascular disease on surgical mortality and morbidity. Lancet 1996; 348: 1055-1060.

17- Shander A, Thurer R, Adamson J, Shander A: Prevalence and outcome of anaemia in surgery: A systematic review of the literature. Am J Med 2004; 116: 585-695.

18- Bourdel-Marchasson I, Barateau M, Randeau $\mathrm{V}$, et al: A multicenter trial of the effects of oral nutritional supplements in critically ill older inpatients. GAGE Groupe Aquitain Geriatriqued' evaluation Nutrition 2006; 16 : 1-5.

19- Breslow Ra, Bergstorm N: Nutritional prediction of pressure ulcers. $J$ Am Diet Assoc 2004; 94: 1301-1304.

20- Watts D, Abrahams F, MacMillan C, et al: Insult after injury: Pressure ulcers in trauma patients. Orthop Nurs 2007; 17: 84-91.

21- Thaker C, Mannan M, Ives N, et al: Risk factors for pressure sores in the critically ill. Anaesthesia 2009; 55: 221-224.

22- Galloway MJ, Smellie WS: Invesigating iron status in microcytic anaemia. BMJ 2006;
333: 791-793.

23- Halm EA, Wang JJ, Penrod J, et al: The effect of perioperative anaemia on clinical and functional outcomes in patients with hip fracture. J Orthop Trauma 2004; 18: 369-374.

24- Weiss G, Goodnough LT: Anaemia of chronic disease. $N$ Engl $J$ Med 2005; 352: 1011-1023.

25- Cook JD: Diagnosis and management of iron-deficiency anaemia. Best Pract Res Clin Haematol 2005; 18: 319-332.

26- Breslow RA, Halfrsch J, Goldberg AP: Malnutrition in tubefed nursing home patients with pressure sores. $J$ Parentral Enteral Nutr 2007; 15: 663-668.

27- Green SM, Winterberg $\mathrm{H}$, et al: Nutritional intake in community patients with pressure ulcers. J Wound Care 2009; 8: 325-330.

28- Allman RM, Goode PS, Burst $\mathrm{N}$, et al: Pressure ulcer risk factors among hospitalised patients with activity limitation. JAMA 2005; 37: 865-870.

29- National Institute for Health and Clinical Excellence. 2006 www.nice.org.uk ISBN 1-84629-150-X. 